\title{
The cultural effect analysis of clothing brand
}

\author{
Yanping $\mathrm{Xie}^{1, \mathrm{a}}$ \\ ${ }^{1}$ Jiangxi Institute of Fashion Technology, Jiangxi, Nanchang, 330201 \\ a42974695@qq.com
}

Keywords: Clothing brand; Cultural effects; Survival; Analysis of the

\begin{abstract}
Clothing brand culture, is a good story for clothing brand, which we should understand the concept of clothing brand, familiar with the role of clothing brand culture exists, and make good use of the role of the brand culture, brand constantly growing, constantly perfect self brand. Analysis of brand, understand brand, clear the relationship between the brand and culture, with the help of brand culture development, the brand has more development space, so as to ensure the development of the enterprise.
\end{abstract}

\section{The introduction}

With the development of economy, people's living standard continuously improving, people also more and more high to the requirement of clothing, clothing is not only used to cover up now clothing, warm, beautiful, unique cultural characteristics are also becoming an important factor to be choose clothes. Apparel rapid development, under the strong pressure of competition, has a unique brand culture of enterprise, it's every series of clothing under the strong culture, has its unique style, set up their own brand and brand culture accomplishment. Unique design style and brand culture to attract customers, good for our enterprise "to cultivate" source of loyal customers, make our products to the aesthetic of the now society, make the brand culture spreading brand better.

Garment industry since the "brand management" as the concept, began to be about "brand" series of products. Brand clothing has certain market foundation, has a more stable consumer groups, so there will be a good market reputation, to promote the brand trademark, there will be more famous trademark. Can form a virtuous cycle, because famous trademark, the product would be better to be publicity, corporate profits will be more and more.

\section{The concept of clothing brand}

Clothing brand as its name implies is clothing trademark. From the brand story more accurate understanding of the brand positioning, brand development direction, and the characteristics of the brand, so that we can distinguish between different products in different enterprises. Brand is the enterprise image and reputation, is a reflection of a commodity attribute. For example, lang and widely accepted are do men's clothing, who give priority to with simple design, contracted and delicate coexist, and the design of the widely from the Chinese traditional culture, Chinese tunic suit, is regarded as the collar. Also do men's clothing, launch site is different, this is the brand, there is a logo.

\section{The classification of the clothing brand design style}

Design style is the soul of the brand clothing design, is the product results. Brand clothing design style is varied, which can be roughly divided into two major categories, the mainstream and tributaries style. Selection in a variety of style or diversity in accordance with enterprise culture image style, established the style, will be looking for style, determine the difference between this style and other styles. Different styles have opposite sex also have similarities. Business style and rigorous style, for example, has the identity, business style is the style of business people, mainly in business wear, will concise refining, sedate and easy, rigorous style of lay particular stress on conservative design elements, the design of the quadrature in the compasses gives a person the sense with concise refining. Lady style and contradict mix building a style, lady style display was a 
romantic and elegant temperament, and mix building a style is more trendy, rock, pursue has the feeling of "high" fashion sense.

\section{Clothing brand culture effect analysis}

Brand culture is the best way to spread the brand. Brand culture is the best way to identify, spreading brand, is the perfect combination of culture and the product. For an example of everyone knows: "made in China" and "created in China" is just a word, it can vary. "China to create", as the name implies it is representing the originality and wisdom, it has a corresponding culture and spirit, and "made in China" is the poor our cheap Labour. The diversification, personalization, complexity of the market, now, more inspired us to Chinese garment enterprise's cultural creativity. From "system" to "a" is necessary, all the way along the way of walking is more emphasized the importance of brand culture. With brand culture transmission, it is a very smart, convenient people understand brand brand culture, understanding the brand is likely to become loyal customers.

Brand clothing brand culture, brand image is a kind of show, the brand culture is deeply rooted in the hearts of the people, to facilitate the spread of brand, this is a brand clothing. Brand culture by giving wonderful and rich cultural connotation, establish clear brand positioning, make full use of strong propagation medium, make consumers understand the brand, create the brand of faith, in the end make consumers loyal "fans".

Brand culture is the core of cultural connotation, it represents is a kind of emotional sustenance, a kind of the belief of anger, show a kind of grade, reveal a kind of fashion, a kind of values determined, in this case the consumers for their favorite brands form a strong sense of dependence and trust, with many good stories and memories, so consumer loyalty for product selection is not just the product value and the function, more is the brand culture, brand beliefs, the choice of brand emotion.

Brand story spread brand culture. Brand story is the more important part of brand culture, almost all the famous brand, there are a frustrated brand story, through artistic processing, in the industry and consumer groups become a kind of cultural transmission. Brand culture idea starts from the brand story, story is spread the concept of brand culture medium, the brand story and the consistency of the brand culture to highly agree better spread the brand culture brand. Luxury brands of expensive for many ordinary people, but, excellent brand story and brand advertising to let them know the brand, the dissemination of the brand.

Brand culture is the foundation of building loyal consumers. A mature brand, has its loyal consumers, and brand culture is the cornerstone of building consumer loyalty. Brand culture is like a label, a brand image. There are a lot of people will stick to wear a certain brand of clothing, or for a certain brand, it is a cultural brand loyal "fans" effect. Someone has done the experiment, for example, pour the pepsi-cola and Coca-Cola, respectively, in the same glass, in people are unwittingly tasting, choose their own likes and dislikes, like Pepsi is far greater than Coca-Cola, but when packing sound of two kinds of drinks on the shelves at the same time, the man who bought Coca-Cola is far greater than Pepsi, that is the cultural brand loyal consumers. A lot of people don't understand, in fact, brand culture to win in the people's psychological consumption. The brand has a kind of intangible value. A successful brand is need time to precipitation, is casting time value, without some years experience of brands is a flash in the pan, for a long time.

Brand culture eagerly anticipates the creativity. Brand culture eagerly anticipates the creativity. Channel brand culture reflected in classical, elegant, luxurious, its products are created under the classical, elegant taste, so the Channel to sell is not only a fashion, it is the mental attitude of a classic and elegant, as shown in figure 1 . Cowboy king Lee, it is not only a cowboy clothing, more freedom, adventure and pioneering spirit of the show, a cowboy amorous feelings. DIOR HOMME melancholy temperament of the British and French delicate combination of nobility, presents an exclusive DIOR HOMME vampire amorous feelings, as shown in figure 2. A variety of examples that the brand culture eagerly anticipates the creativity. Brand culture is a kind of symbol, can lead the creativity. 


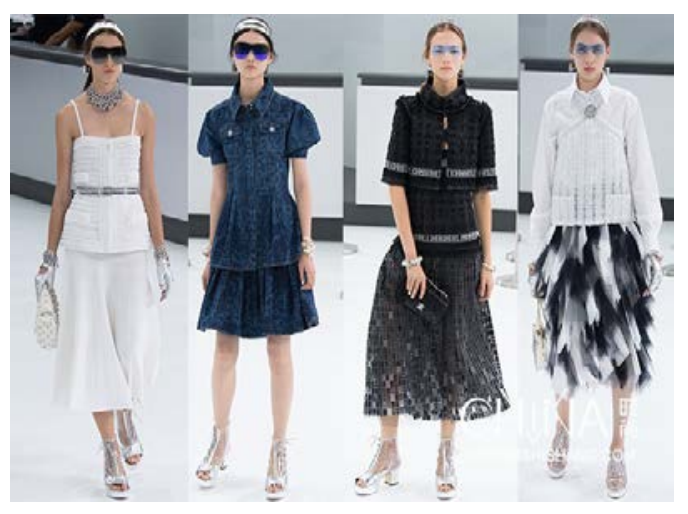

Fig.1 The Channel ladies'

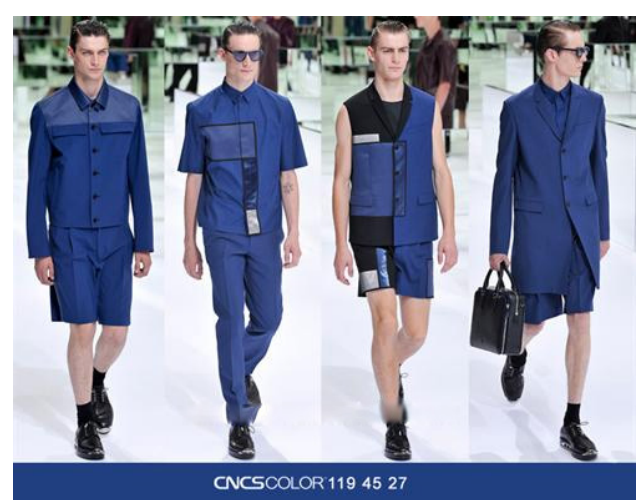

Fig. 2 Men's clothing of DIOR HOMME

Clothing brand culture to the enterprise brought a lot of favorable conditions. First, brand culture is helpful for consumers to understand product, so that they identify themselves in a pile of similar products of the brand products, this is a recognition of product difference. Second, adjust the enterprise resources, enterprise resources more reasonable use, and to achieve an optimal state. Third, help enterprises to enhance competitiveness, to the enterprise products to create a broader market. Fourth, with the aid of the cultural development of brand, brand communication gives brand more color, so that consumers remember the brand, only remember the brand, is likely to become loyal customers. The combination of these four aspects for the enterprise to develop the brand culture provides the basis and direction.

Clothing brand culture of make consumers fully understand the characteristics of the products under the brand, brand culture and brand characteristics of the product has a very high consistency, it is advantageous to the recognition of the similarity product, thus forming a kind of consumer's choice of brand loyalty.

Enterprise resources integration is the enterprise management must study a course, learn enterprise resource integration, is a business strategy method is mastered. Integration is to optimize the allocation of resources, want to have a kind of elastic, have increased, and shrinkage, achieve overall most sorrow. Now many enterprises are in a bad state, include: this kind of undesirable state of the homogeneity of products, sales model popularisation, service system and lack of brand consciousness is weak, the malignant market competition, and to minimize the economic benefits of the. Companies in these unhealthy atmosphere is very difficult to make resources get the most reasonable maximum is applied. Continuous integration resources can make our super strengthen enterprise branding, marketing mode innovation, economic benefit maximization, service value, minimise competition in the market.

Clothing brand culture brought advantages for the enterprise the competitive ability, this is a virtuous cycle. Brand culture, brand culture brand characteristics, so as to promote enterprise competitiveness of ascension, the integration of the transmission effect is better optimization of transmission channel, and purify the communication content. Good culture to create a good brand, good brand story spread good emotional sustenance, make consumers to the brand has a unique spirit of dependence.

\section{Conclusion}

The carrier is strong in the development of clothing clothing brand culture. With the development of The Times, people into the information age, what all want to pay attention to reputation and credibility problems, naturally have the brand development space, quickly made the development of brand culture, so now has all kinds of brand culture appeared in people's life. Clothing brand has a certain social and economic function, it includes value, culture and personality, and clothing brand culture influence will be a focus of the Chinese clothing market a new round of competition, the future of enterprise competition is a competition of brand, but also the competition between brand culture, it is a high level of competition, any a successful enterprise with its unique brand culture shifting alliances in the market. Brand selling is a kind of culture, a kind of state, a kind of essence 
of consumers want to buy inner driving force.

\section{Reference}

[1] Linling Tian. In the clothing brand culture effect analysis [J]. Market modernization, 2013 (05). [2] Liu ye. Celebrity endorsement for brand shaping and effect analysis [J]. Science and technology, 2015 (02).

[3] Yan chao. Clothing brand effect on consumers' cognitive source [J]. Journal of textile, 2001 (7). 